\title{
Tumor suppressive microRNA-375 regulates lactate dehydrogenase $B$ in maxillary sinus squamous cell carcinoma
}

\author{
TAKASHI KINOSHITA ${ }^{1,2}$, NIJIRO NOHATA ${ }^{1,2}$, HIROFUMI YOSHINO ${ }^{3}$, TOYOYUKI HANAZAWA ${ }^{2}$, \\ NAOKO KIKKAWA $^{2}$, LISA FUJIMURA ${ }^{4}$, TAKESHI CHIYOMARU ${ }^{3}$, KAZUMORI KAWAKAMI $^{3}$, \\ HIDEKI ENOKIDA $^{3}$, MASAYUKI NAKAGAWA ${ }^{3}$, YOSHITAKA OKAMOTO ${ }^{2}$ and NAOHIKO SEKI ${ }^{1}$ \\ Departments of ${ }^{1}$ Functional Genomics, ${ }^{2}$ Otorhinolaryngology/Head and Neck Surgery, Chiba University \\ Graduate School of Medicine, 1-8-1 Inohana Chuo-ku, Chiba 260-8670; ${ }^{3}$ Department of Urology, Graduate \\ School of Medical and Dental Sciences, Kagoshima University, 8-35-1 Sakuragaoka, Kagoshima 890-8520; \\ ${ }^{4}$ Biomedical Research Center, Chiba University, 1-8-1 Inohana Chuo-ku, Chiba 260-8670, Japan
}

Received July 6, 2011; Accepted August 23, 2011

DOI: 10.3892/ijo.2011.1196

\begin{abstract}
The expression of microRNA-375 (miR-375) is significantly reduced in cancer tissues of maxillary sinus squamous cell carcinoma (MSSCC). The aim of this study was to investigate the functional significance of $m i R-375$ and a possible regulatory role in the MSSCC networks. Restoration of $m i R-375$ significantly inhibited cancer cell proliferation and invasion in IMC-3 cells, suggesting that $m i R-375$ functions as a tumor suppressor in MSSCC. Genome-wide gene expression data and luciferase reporter assays indicated that lactate dehydrogenase $B$ $(L D H B)$ was directly regulated by $m i R-375$. Cancer cell proliferation and invasion were significantly inhibited by transfection of si- $L D H B$ into IMC-3 cells, suggesting that $L D H B$ may play a role in MSSCC oncogenic function. In clinical MSSCC specimens, $L D H B$ mRNA levels were up-regulated in cancer tissues, which were inversely correlated with the expression of $m i R-375$. In addition, Kaplan-Meier curves and log-rank tests revealed that the high mRNA expression levels of $L D H B$ had a significant adverse effect on survival rate. The identification of a cancer network regulated by the $m i R-375$ tumor suppressor could provide new insights into the molecular mechanisms of MSSCC oncogenesis.
\end{abstract}

\section{Introduction}

Maxillary sinus squamous cell carcinoma (MSSCC) is a malignant epithelial tumor originating in the respiratory mucosa of the maxillary sinus. MSSCC comprises 2-3\% of all

Correspondence to: Dr Naohiko Seki, Department of Functional Genomics, Chiba University Graduate School of Medicine, 1-8-1 Inohana Chuo-ku, Chiba 260-8670, Japan

E-mail: naoseki@faculty.chiba-u.jp

Key words: microRNA, miR-375, lactate dehydrogenase B, maxillary sinus squamous cell carcinoma, tumor suppressor head and neck tumors, with an annual incidence of 0.5-1.0 per 100,000 people $(1,2)$. Since the clinical symptoms of patients with MSSCC are very insidious, tumors are often diagnosed at advanced stages. Despite advances in multimodality therapy including surgery, radiotherapy and chemotherapy, the 5-year survival rate for MSSCC has remained $~ 50 \%$. Although regional lymph node metastasis and distant metastasis are uncommon (20\%), the high rate of locoregional recurrence $(60 \%)$ contributes to poor survival (3). The results of epidemiological studies have suggested that occupational exposures to leather, wood dust, nickel, arsenic and formaldehyde are risk factors for MSSCC (4-6); a point of divergence from head and neck squamous cell carcinomas (HNSCC) of the tongue, oral cavity and pharynx. Few reports have performed genome analysis of MSSCC. Understanding the molecular oncogenic pathways underlying MSSCC could significantly improve diagnosis, therapy, and disease prevention.

Growing evidence suggests that carcinogenesis is induced by overactivation of pro-oncogenic pathways and inactivation of tumor-suppressive pathways (7). In cancer pathways, normal regulatory mechanisms are disrupted by aberrant expression of microRNA (miRNA) (8). miRNAs are a class of small non-coding RNA molecules consisting of 19-22 nucleotides that are involved in a variety of biological processes including development, differentiation, apoptosis, and cell proliferation. They regulate gene expression through translational repression and mRNA cleavage (9). Bioinformatic predictions indicate that miRNAs regulate $>30 \%$ of protein coding genes (10). So far, 1424 human miRNAs have been registered at miRBase release 17.0 (http://microrna.sanger.ac.uk/). miRNAs contribute to the initiation and development of various types of cancers (11). miRNAs are aberrantly expressed in many human cancers, and can function either as tumor suppressors or oncogenes (12).

Down-regulated miRNAs in cancer cells might normally function as tumor suppressive miRNAs that negatively regulate oncogenes. Based on this hypothesis, we have profiled the miRNA expression signatures of human cancers, including HNSCC (13-17). In human squamous cell carcinoma (SCC), tumor suppressive miRNAs such as $m i R-1, m i R-133 a$ and 
$m i R-489$ were identified through direct repression of several oncogenes $(15,16,18-20)$. The miRNA expression signatures of hypopharyngeal SCC, esophageal SCC and MSSCC revealed that $m i R-375$ is significantly reduced in cancer cells $(15,16)$. $m i R-375$ was originally cloned and identified as an evolutionarily conserved pancreatic islet-specific miRNA (21). $m i R-375^{-/}$mice were hyperglycemic and exhibited an increase in the number of pancreatic $\alpha$ cells (22). Although several studies have indicated that $m i R-375$ is down-regulated in human cancers, the function of $m i R-375$ and its target genes in MSSCC remains unclear (23-26).

The aim of this study was to clarify the functional significance of $m i R-375$ in MSSCC and to identify molecular pathways regulated by $m i R-375$. We analyzed the effect of $m i R-375$ on cell proliferation and cell invasion in the MSSCC cell line IMC-3. Genome-wide expression analysis identified lactate dehydrogenase $B(L D H B)$ as a candidate gene target of $m i R-375$. The identification of a novel $m i R$-375-regulated tumor suppressive pathway could further reveal the molecular mechanism of MSSCC oncogenesis.

\section{Materials and methods}

MSSCC cell culture. IMC-3, a human MSSCC cell line, was derived from a primary lesion of MSSCC (27). MSSCC cells were grown in RPMI-1640 medium supplemented with $10 \%$ fetal bovine serum in a humidified atmosphere containing $5 \%$ $\mathrm{CO}_{2}$ at $37^{\circ} \mathrm{C}$.

Clinical specimens of MSSCC. Written consent for tissue donation for research purposes was obtained from each patient before tissue collection. The protocol was approved by the Institutional Review Board of Chiba University. Twenty pairs of primary tumor tissues and corresponding normal epithelial tissues were obtained from patients with MSSCC in Chiba University Hospital (Chiba, Japan) from 2007 to 2010. The normal tissue was confirmed to be free of cancer cells by pathologic examination. The specimens were immersed in RNAlater (Qiagen, Valencia, CA, USA) and stored at $-20^{\circ} \mathrm{C}$ until RNA was extracted. Clinical information of the twenty patients is shown in Table I.

RNA isolation. Total RNA was isolated using TRIzol Reagent (Invitrogen, Carlsbad, CA, USA) according to the manufacturer's protocol. RNA concentration was determined spectrophotometrically, and molecular integrity was checked by gel electrophoresis. RNA quality was confirmed using an Agilent 2100 Bioanalyzer (Agilent Technologies, Santa Clara, CA, USA).

Mature miRNA transfection and small interfering RNA treatment. The following RNA species were used in this study: mature miRNAs, Pre-miRTM miRNA Precursors (hsa-miR375; Pre-miR ID: PM10327), negative control miRNA (P/N: AM17111) (Applied Biosystems, Foster City, CA, USA), small interfering RNA (Stealth Select RNAi ${ }^{\mathrm{TM}}$ siRNA; si- $L D H B$ Cat. no.; HSS106003 and HSS106004) (Invitrogen) and negative control siRNA (Stealth ${ }^{\mathrm{TM}}$ RNAi Negative Control Medium GC Duplex; 12935-300) (Invitrogen). RNAs were incubated with Opti-MEM (Invitrogen) and Lipofectamine ${ }^{\mathrm{TM}}$ RNAiMax
Reagent (Invitrogen) as described previously (13). Transfection efficiency of Pre-miRTM in the IMC-3 cell line was confirmed based on down-regulation of TWF1 (PTK9) mRNA following transfection with $m i R-1$ as previously reported $(14,15)$.

Cancer cell proliferation and invasion assays. Cells were transfected with $10 \mathrm{nM}$ miRNA and siRNA by reverse transfection and plated in 96-well plates at $3 \times 10^{3}$ cells per well. After 72 or $96 \mathrm{~h}$, cell proliferation was determined with the XTT assay, using the Cell Proliferation kit II (Roche Molecular Biochemicals, Mannheim, Germany) as previously reported $(15,16)$. Triplicate wells were measured for cell viability in each treatment group.

A cell invasion assay was carried out using modified Boyden chambers containing transwell-precoated Matrigel membrane filter inserts with $8-\mu \mathrm{m}$ pores in 24-well tissue culture plates at $1 \times 10^{5}$ cells per well (BD Biosciences, Bedford, MA, USA) (14). Triplicate wells were measured for cell invasion in each treatment group.

Microarray expression analysis. A genome-wide screen was performed to identify gene targets of $m i R-375$ in the IMC-3 cell line. Oligo-microarray Human 44K (Agilent Technologies) was used for expression profiling of miR-375 transfectants in comparison with miRNA-negative-control transfectants. Microarray hybridization and data collection were performed as previously described (28). TargetScan (release 5.1, http:// www.targetscan.org/) was used to identify predicted target genes and their miRNA binding site seed regions. Sequences of the predicted mature miRNAs were confirmed using miRBase (release 17.0, http://microrna.sanger.ac.uk/).

Quantitative reverse-transcription- $P C R(q R T-P C R)$. Firststrand cDNA was synthesized from $1.0 \mu \mathrm{g}$ of total RNA using a High Capacity cDNA Reverse Transcription kit (Applied Biosystems). Gene-specific PCR products were assayed continuously using a 7900-HT Real-Time PCR System according to the manufacturer's protocol. TaqMan ${ }^{\circledR}$ probes and primers for $L D H B(\mathrm{P} / \mathrm{N}$ : Hs00929956_m1), and GUSB $(\mathrm{P} / \mathrm{N}$ : Hs99999908_m1) internal control were obtained from Applied Biosystems (Assay-On-Demand Gene Expression Products). The expression levels of $m i R-375$ (Assay ID: 000564) was analyzed by TaqMan quantitative real-time PCR (TaqMan MicroRNA Assay; Applied Biosystems) and normalized to RNU48 (Assay ID: 001006). All reactions were performed in triplicate, and included negative control reactions that lacked cDNA.

Western blot analysis. Cells were harvested and lysed $72 \mathrm{~h}$ after transfection. Each cell lysate (50 $\mu \mathrm{g}$ of protein) was separated using Mini-PROTEAN TGX gels (Bio-Rad, Hercules, CA, USA) and transferred to PVDF membranes. Immunoblotting was performed with monoclonal LDHB antibody (1:10000) (2090-1; Epitomics, Burlingame, CA, USA). GAPDH antibody (1:1000) (ab8245; AbCam, Cambridge, UK) was used as an internal control. The membrane was washed and incubated with goat anti-rabbit IgG (H+L)-HRP conjugate (Bio-Rad). Complexes were visualized with an Immun-Star WesternC chemiluminescence kit (Bio-Rad), and the expression levels of these proteins were evaluated by ImageJ software (version 1.44; http://rsbweb.nih.gov/ij/index.html). 
Table I. Clinical information of 20 patients with MSSCC.

\begin{tabular}{rrrccccc}
\hline No. & Age & Gender & Differentiation & $\mathrm{T}$ & $\mathrm{N}$ & $\mathrm{M}$ & Stage \\
\hline 1 & 68 & Male & Well & $4 \mathrm{~b}$ & 0 & 0 & IVB \\
2 & 77 & Male & Poor & 3 & 0 & 0 & III \\
3 & 76 & Male & Moderate & 3 & 0 & 0 & III \\
4 & 61 & Male & Well & 3 & 0 & 0 & III \\
5 & 54 & Male & Poor & 3 & 0 & 0 & III \\
6 & 65 & Female & Poor & $4 \mathrm{~b}$ & 0 & 0 & IVB \\
7 & 65 & Male & Moderate & $4 \mathrm{a}$ & 0 & 0 & IVA \\
8 & 64 & Male & Poor & $4 \mathrm{~b}$ & 0 & 0 & IVB \\
9 & 74 & Male & Well & $4 \mathrm{a}$ & 0 & 0 & IVA \\
10 & 71 & Male & Moderate & 3 & 1 & 0 & III \\
11 & 64 & Male & Moderate & $4 \mathrm{a}$ & 0 & 0 & IVA \\
12 & 80 & Male & Moderate & $4 \mathrm{a}$ & 0 & 0 & IVA \\
13 & 66 & Female & Poor & $4 \mathrm{a}$ & $2 \mathrm{c}$ & 0 & IVA \\
14 & 67 & Male & Moderate & $4 \mathrm{a}$ & 0 & 0 & IVA \\
15 & 60 & Male & Poor & $4 \mathrm{a}$ & 0 & 0 & IVA \\
16 & 66 & Female & Moderate & $4 \mathrm{a}$ & 0 & 0 & IVA \\
17 & 85 & Male & Poor & $4 \mathrm{a}$ & 0 & 0 & IVA \\
18 & 69 & Male & Well & $4 \mathrm{a}$ & 0 & 0 & IVA \\
19 & 57 & Male & Poor & $4 \mathrm{a}$ & 0 & 0 & IVA \\
20 & 69 & Male & Poor & $4 \mathrm{a}$ & $2 \mathrm{~b}$ & 0 & IVA \\
\hline
\end{tabular}

Plasmid construction and dual-luciferase reporter assay. The wild-type sequence of the $L D H B$ 3'-UTR (WT-3'UTR) and a sequence with deleted $m i R-375$ target sites (DEL-3'UTR) were inserted between the XhoI-PmeI restriction sites in the 3'UTR of the hRluc gene in the psiCHECK-2 vector (C8021; Promega, Madison, WI). IMC-3 cells were transfected with $15 \mathrm{ng}$ of vector, $10 \mathrm{nM}$ of miR-375 (Applied Biosystems), and $1 \mu 1$ of Lipofectamine 2000 (Invitrogen) in $100 \mu 1$ of Opti-MEM (Invitrogen). The activities of Firefly and Renilla luciferases in cell lysates were determined with a dual-luciferase assay system (E1910; Promega). Normalized data were calculated as the quotient of Renilla/Firefly luciferase activities.

Statistical analysis. The relationships between two groups and the numerical values obtained by qRT-PCR were analyzed using the nonparametric Mann-Whitney $U$ test or the paired t-test. The relationship among more than three variables and numerical values was analyzed using the Bonferroni adjusted Mann-Whitney U test. Spearman's rank test was used to evaluate the relationships among the relative expression levels of miR375 and $L D H B$ mRNA. The Kaplan-Meier method was performed using a median split method in which patients were divided into 2 groups on the basis of whether mRNA expression levels were higher or lower than the median. The log-rank test was used to compare curves. All analyses were performed using Expert StatView (version 4, SAS Institute Inc., Cary, NC, USA).

\section{Results}

Effect of miR-375 transfection on proliferation and invasion in IMC-3 cells. The functional significance of $m i R-375$ was evaluated with a gain-of-function assay using $m i R$-375 transfectants. The XTT assay showed significant inhibition of cell proliferation in $m i R-375$ transfectants in comparison with mock and miRNA-control transfectants after $72 \mathrm{~h}$ (\% of cell proliferation, $60.9 \pm 1.0,100.0 \pm 3.3$ and $103.0 \pm 2.6$, respectively, $\mathrm{P}<0.0001)$ and after $96 \mathrm{~h}$ (\% of cell proliferation, 51.0 \pm 2.6 , $100.0 \pm 2.6$ and $117.3 \pm 8.3$, respectively, $\mathrm{P}<0.0001$ ) (Fig. 1A).

The Matrigel invasion assay demonstrated that invading cell numbers were significantly decreased in $m i R-375$ transfectants compared to mock and miRNA-control transfectants (\% of cell invasion, 46.4 $\pm 2.4,100.0 \pm 14.2$ and $98.7 \pm 3.9$, respectively, $\mathrm{P}=0.0005)$ (Fig. 1B).

Screening of miR-375 target genes using gene expression analysis. To gain further insight into which protein-coding genes are regulated by $m i R-375$ in IMC-3 cells, we performed comprehensive gene expression analysis with $m i R$-375 transfectants. miRNA-control transfectants that produced raw signal values of $<3,000$ were excluded before comparisons were made. Fifty-two genes were down-regulated less than $-1.0\left(\log _{2}\right.$ ratio) in the transfectants (Table II). The 3'UTR of these downregulated genes were examined for the existence of $m i R-375$ target sites using the TargetScan database. TargetScan revealed that 28 of the 52 genes had putative $m i R-375$ target sites in their 3'UTR (Table II).

miR -375 regulation of lactate dehydrogenase $B(L D H B)$. The $L D H B$ gene was chosen for further study because it ranked at the top of the list of candidate genes in the genome-wide gene expression analysis and had one putative miR-375 target site. qRT-PCR revealed that the expression level of $L D H B$ mRNA 
A
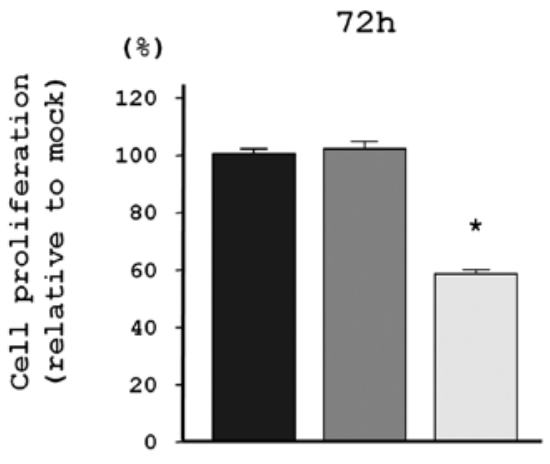

B

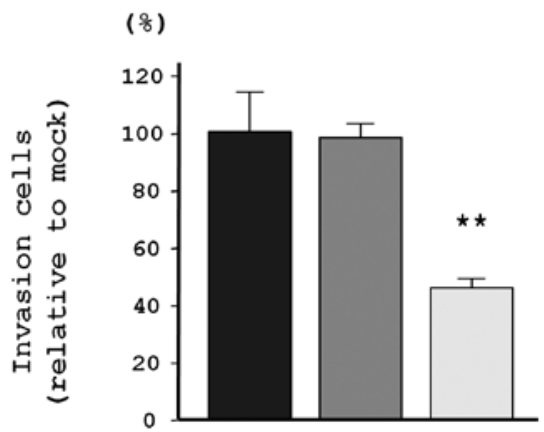

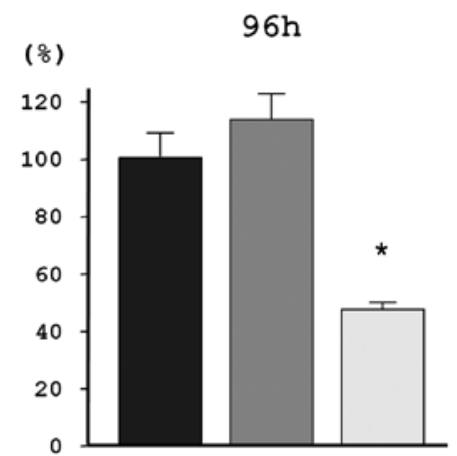

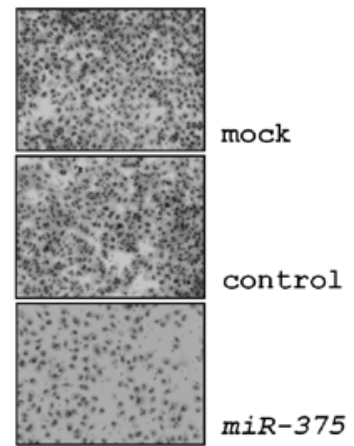

$\square$ mock

control

$\operatorname{miR}-375$

Figure 1. Gain-of-function studies using $m i R-375$ transfected IMC-3 cells. (A) Cell proliferation as revealed by the XTT assay 72 and $96 \mathrm{~h}$ after transfection ${ }^{*} \mathrm{P}<0.0001$. (B) Cell invasion activity (Matrigel invasion assay) in IMC-3 cells $48 \mathrm{~h}$ after transfection with $m i R-375$. ${ }^{* *} \mathrm{P}=0.0005$.

A

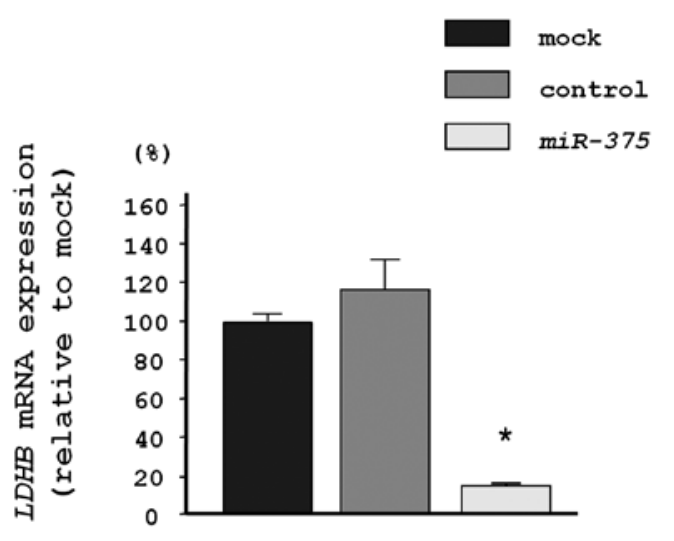

B

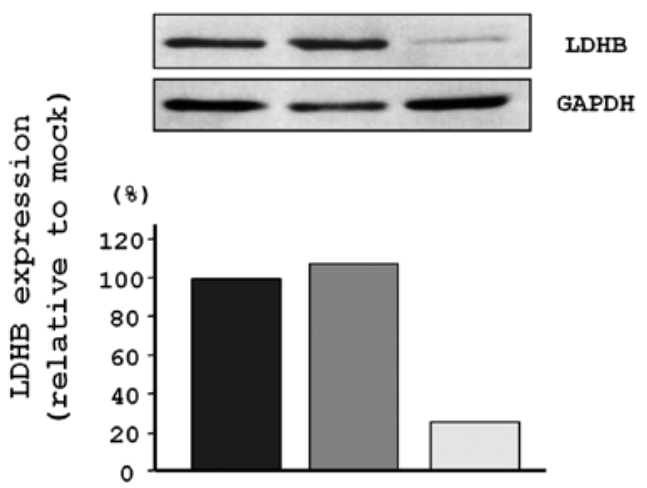

Figure 2. LDHB mRNA and protein expression in IMC-3 cells. (A) qRT-PCR revealed that $L D H B$ mRNA was significantly repressed in $m i R-375$ transfectants compared with mock and control. GUSB was used as an internal control. ${ }^{*} \mathrm{P}<0.0001$. (B) Western blotting revealed that LDHB protein expression was also decreased in the miR-375 transfectant. GAPDH was used as a loading control.

was significantly repressed in $m i R-375$ transfected IMC-3 cells compared to mock controls (Fig. 2A). Protein expression was also markedly reduced in $m i R-375$ transfectants (Fig. 2B).

A luciferase reporter assay was then used to confirm that the predicted binding site was an actual target of $m i R-375$. We used a vector encoding either the total sequence of the $L D H B$ 3'UTR, including the predicted miR-375 target site (positions 171-177), or a vector lacking the $m i R-375$ target site. Luminescence intensity was significantly reduced by transfection of the entire $L D H B$ 3'UTR, while deletion of positions 171-177 blocked the decrease in luminescence (Fig. 3).

Effect of LDHB silencing on cell proliferation and invasion. The functional role of $L D H B$ was examined with loss-offunction studies using IMC-3 cells transfected with two different si- $L D H B$ s. The mRNA and protein levels were markedly reduced in si- $L D H B$ transfectants (Fig. $4 \mathrm{~A}$ and B).

The XTT assay revealed significant inhibition of cell proliferation in si- $L D H B$ transfectants in comparison with mock 
Table II. Down-regulated genes in $m i R-375$ transfectant of IMC-3.

\begin{tabular}{|c|c|c|c|c|c|}
\hline No. & $\begin{array}{c}\text { Entrez } \\
\text { gene ID }\end{array}$ & $\begin{array}{l}\text { Gene } \\
\text { symbol }\end{array}$ & Gene name & $\begin{array}{l}\log _{2} \\
\text { ratio }\end{array}$ & $\begin{array}{l}m i R-375 \\
\text { target site }\end{array}$ \\
\hline 1 & 3945 & $L D H B$ & Lactate dehydrogenase B & -1.82 & 1 \\
\hline 2 & 7534 & $\begin{array}{l}Y W H A Z / \\
14-3-3 \zeta\end{array}$ & 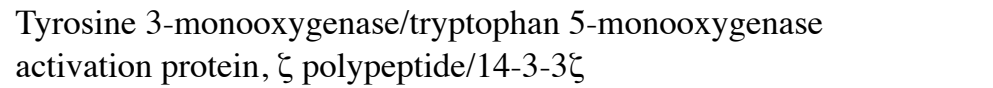 & -1.69 & 1 \\
\hline 3 & 3516 & $R B P J$ & Recombination signal binding protein for immunoglobulin $\kappa \mathrm{J}$ region & -1.65 & 1 \\
\hline 4 & 57179 & KIAA1191 & KIAA1191 & -1.60 & 1 \\
\hline 5 & 114569 & $M A L 2$ & Mal, T-cell differentiation protein 2 & -1.60 & 1 \\
\hline 6 & 5420 & PODXL & Podocalyxin-like & -1.57 & 2 \\
\hline 7 & 84650 & $E B P L$ & Emopamil binding protein-like & -1.52 & 1 \\
\hline 8 & 10857 & PGRMC1 & Progesterone receptor membrane component 1 & -1.52 & 0 \\
\hline 9 & 4023 & $L P L$ & Lipoprotein lipase & -1.51 & 1 \\
\hline 10 & 92140 & $A E G-1 / M T D H$ & Astrocyte elevated gene-1/metadherin & -1.47 & 1 \\
\hline 11 & 5052 & PRDX1 & Peroxiredoxin 1 & -1.47 & 1 \\
\hline 12 & 6418 & SET & SET nuclear oncogene & -1.40 & 1 \\
\hline 13 & 4609 & $M Y C$ & V-Myc myelocytomatosis viral oncogene homolog (avian) & -1.40 & 0 \\
\hline 14 & 708 & $C 1 Q B P$ & Complement component $1, \mathrm{q}$ subcomponent binding protein & -1.39 & 1 \\
\hline 15 & 55177 & $F A M 82 A 2$ & Family with sequence similarity 82, member A2 & -1.33 & 1 \\
\hline 16 & 5504 & $P P P 1 R 2$ & Protein phosphatase 1 , regulatory (inhibitor) subunit 2 & -1.27 & 0 \\
\hline 17 & 10314 & LANCL1 & LanC lantibiotic synthetase component C-like 1 (bacterial) & -1.21 & 2 \\
\hline 18 & 114971 & PTPMT1 & Protein tyrosine phosphatase, mitochondrial 1 & -1.20 & 1 \\
\hline 19 & 9601 & PDIA4 & Protein disulfide isomerase family A, member 4 & -1.20 & 0 \\
\hline 20 & 9221 & NOLCl & Nucleolar and coiled-body phosphoprotein 1 & -1.19 & 2 \\
\hline 21 & 442249 & LOC442249 & Similar to keratin 18 & -1.18 & 0 \\
\hline 22 & 50999 & TMED5 & Transmembrane emp 24 protein transport domain containing 5 & -1.17 & 1 \\
\hline 23 & 5037 & PEBP1 & Phosphatidylethanolamine binding protein 1 & -1.16 & 0 \\
\hline 24 & 159 & $A D S S$ & Adenylosuccinate synthase & -1.16 & 0 \\
\hline 25 & 9156 & EXO1 & Eexonuclease 1 & -1.16 & 0 \\
\hline 26 & 284085 & FLJ40504 & Keratin 18 pseudogene & -1.16 & 0 \\
\hline 27 & 22856 & CHSY1 & Chondroitin sulfate synthase 1 & -1.14 & 1 \\
\hline 28 & 90133 & KRT8P12 & Keratin 8 pseudogene 12 & -1.13 & 0 \\
\hline 29 & 9802 & $D A Z A P 2$ & DAZ associated protein 2 & -1.13 & 1 \\
\hline 30 & 5557 & PRIM1 & Primase, DNA, polypeptide 1 (49 kDa) & -1.12 & 0 \\
\hline 31 & 55536 & $C D C A 7 L$ & Cell division cycle associated 7-like & -1.12 & 2 \\
\hline 32 & 9343 & EFTUD2 & Elongation factor Tu GTP binding domain containing 2 & -1.12 & 0 \\
\hline 33 & 116228 & FAM36A & Family with sequence similarity 36, member A & -1.11 & 0 \\
\hline 34 & 9709 & HERPUD1 & $\begin{array}{l}\text { Homocysteine-inducible, endoplasmic reticulum } \\
\text { stress-inducible, ubiquitin-like domain member } 1\end{array}$ & -1.11 & 1 \\
\hline 35 & 10360 & NPM3 & Nucleophosmin/nucleoplasmin 3 & -1.10 & 0 \\
\hline 36 & 3856 & KRT8 & Keratin 8 & -1.09 & 0 \\
\hline 37 & 528 & ATP6V1C1 & ATPase, $\mathrm{H}^{+}$transporting, lysosomal $42 \mathrm{kDa}, \mathrm{V} 1$ subunit $\mathrm{C} 1$ & -1.08 & 1 \\
\hline 38 & 5955 & $R C N 2$ & Reticulocalbin 2, EF-hand calcium binding domain & -1.08 & 0 \\
\hline 39 & 9493 & KIF 23 & Kinesin family member 23 & -1.08 & 0 \\
\hline 40 & 26521 & $T I M M 8 B$ & Translocase of inner mitochondrial membrane 8 homolog B (yeast) & -1.08 & 0 \\
\hline 41 & 332 & BIRC5 & Baculoviral IAP repeat-containing 5 & -1.07 & 0 \\
\hline 42 & 1063 & CENPF & Centromere protein F, 350/400 ka (mitosin) & -1.06 & 0 \\
\hline 43 & 10960 & LMAN2 & Lectin, mannose-binding 2 & -1.06 & 0 \\
\hline 44 & 1478 & CSTF2 & Cleavage stimulation factor, $3^{\prime}$ pre-RNA, subunit 2, $64 \mathrm{kDa}$ & -1.05 & 1 \\
\hline 45 & 112950 & $M E D 8$ & Mediator complex subunit 8 & -1.05 & 1 \\
\hline 46 & 3099 & $H K 2$ & Hexokinase 2 & -1.05 & 0 \\
\hline 47 & 11335 & $C B X 3$ & Chromobox homolog 3 (HP1 $\gamma$ homolog, Drosophila) & -1.04 & 1 \\
\hline 48 & 10440 & TIMM17A & Translocase of inner mitochondrial membrane 17 homolog A (yeast) & -1.03 & 1 \\
\hline 49 & 11113 & $C I T$ & Citron (rho-interacting, serine/threonine kinase 21) & -1.03 & 1 \\
\hline 50 & 8727 & CTNNAL1 & Catenin (cadherin-associated protein), $\alpha$-like 1 & -1.01 & 0 \\
\hline 51 & 3875 & KRT18 & Keratin 18 & -1.01 & 0 \\
\hline 52 & 9804 & TOMM20 & Translocase of outer mitochondrial membrane 20 homolog (yeast) & -1.00 & 2 \\
\hline
\end{tabular}



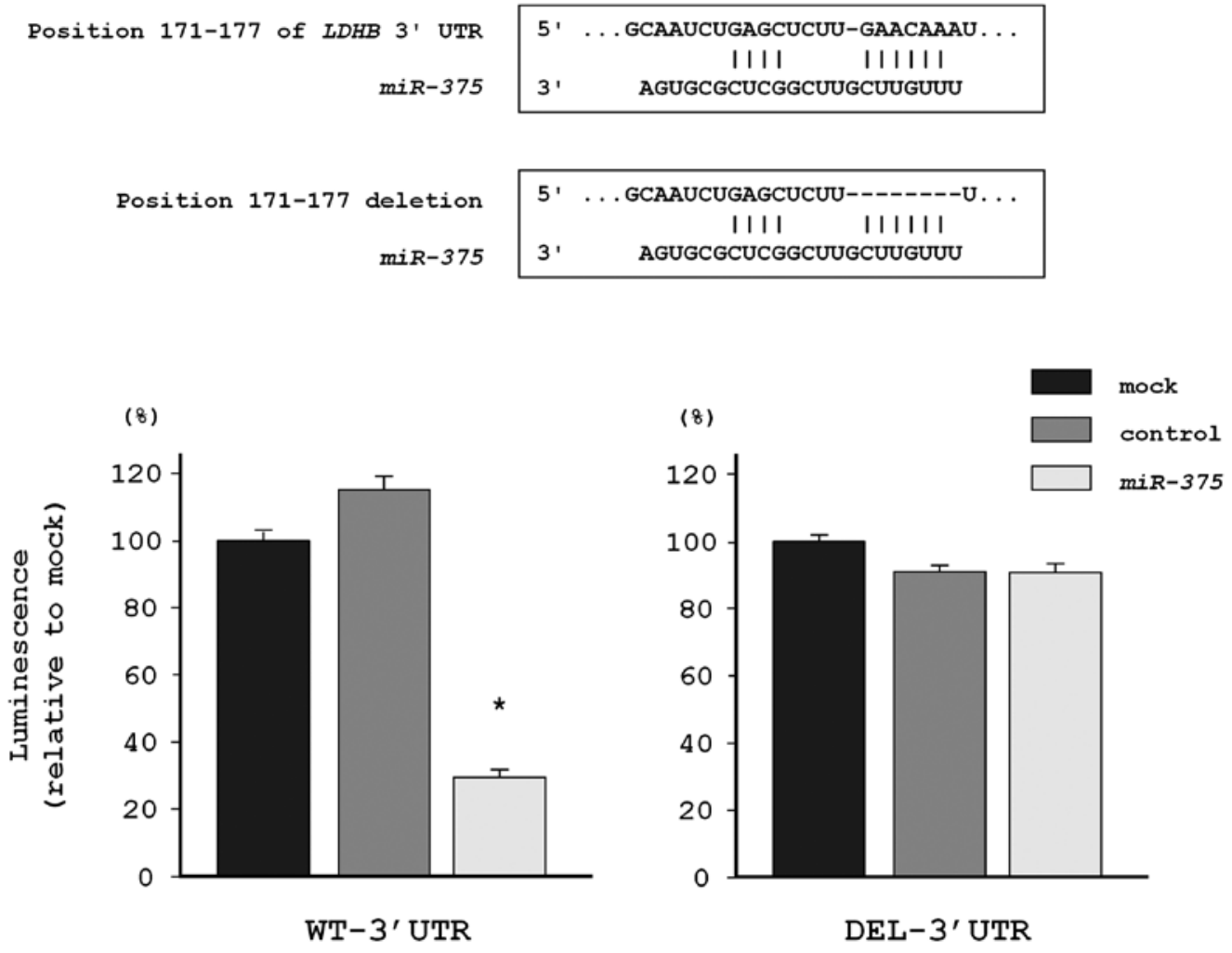

Figure 3. Interaction of $m i R-375$ with the $L D H B 3^{\prime} \mathrm{UTR}$. At $24 \mathrm{~h}$ after transfection (with $10 \mathrm{nM} m i R-375$ or miRNA-control) or mock transfection, a reporter plasmid containing $L D H B$ WT-3'UTR or DEL-3'UTR and a plasmid expressing Renilla luciferase (hRluc) were co-transfected into IMC-3 cells. Firefly luciferase activity was normalized to Renilla luciferase activity. ${ }^{*} \mathrm{P}<0.0001$.

A

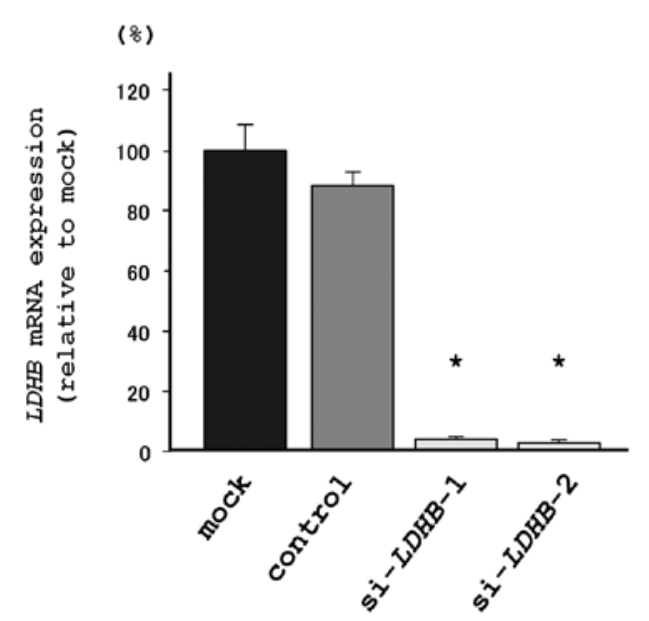

B
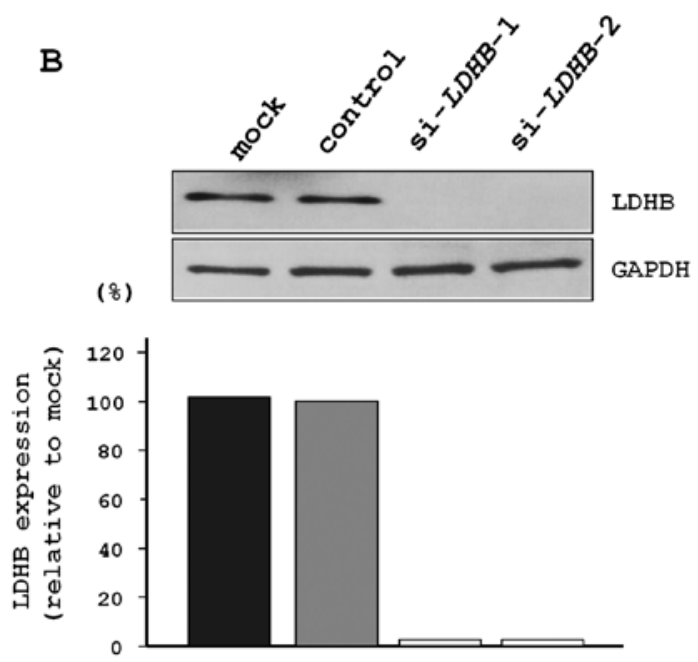

Figure 4. siRNA knockdown of $L D H B$ in IMC-3 cells. (A) qRT-PCR revealed that $L D H B$ mRNA was significantly repressed in si- $L D H B$ transfectants compared with mock and si-controls. GUSB was used as an internal control ${ }^{*} \mathrm{P}<0.0001$. (B) Western blot analysis revealed that LDHB protein expression was also decreased in $\mathrm{si}-L D H B$ transfectants. GAPDH was used as a loading control.

and si-control transfectants after $72 \mathrm{~h}(\%$ of cell proliferation: $83.6 \pm 2.1,83.4 \pm 3.0,100.0 \pm 5.0$ and $99.3 \pm 3.0$, respectively, $\mathrm{P}<0.0005$; Fig. 5A) and $96 \mathrm{~h}$ (\% of cell proliferation: 64.0 \pm 1.1 , $67.8 \pm 2.6,100.0 \pm 1.4$ and $96.8 \pm 0.8$, respectively, $\mathrm{P}<0.0001$; Fig. 5A).

The Matrigel invasion assay demonstrated that the number of invading cells was significantly lower in the si- $L D H B$ trans- fectants compared with mock and si-control transfectants $(\%$ of cell invasion, $15.3 \pm 2.8,12.2 \pm 3.2,100.0 \pm 14.7$ and $77.8 \pm 4.8$ respectively, $\mathrm{P}<0.0001$ ) (Fig. 5B).

Expression levels of miR-375 and LDHB in MSSCC clinical specimens. The expression level of $m i R-375$ was significantly down-regulated in clinical MSSCC specimens compared with 
A $(8)$

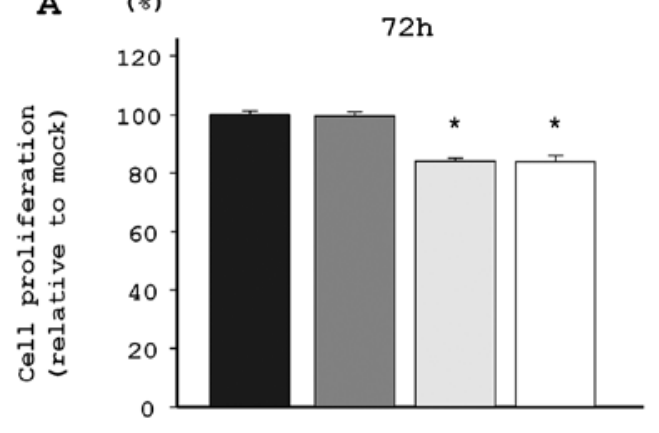

B $(8)$

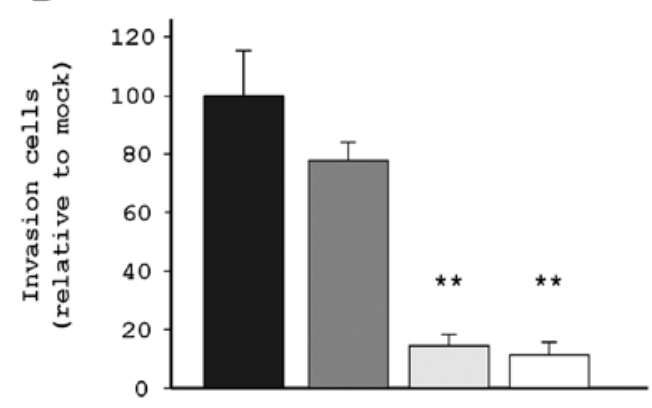

(8)

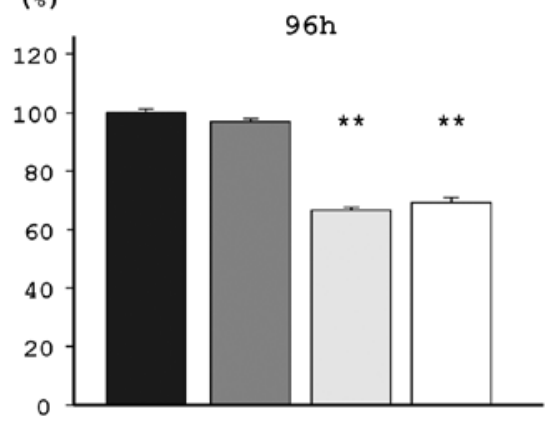

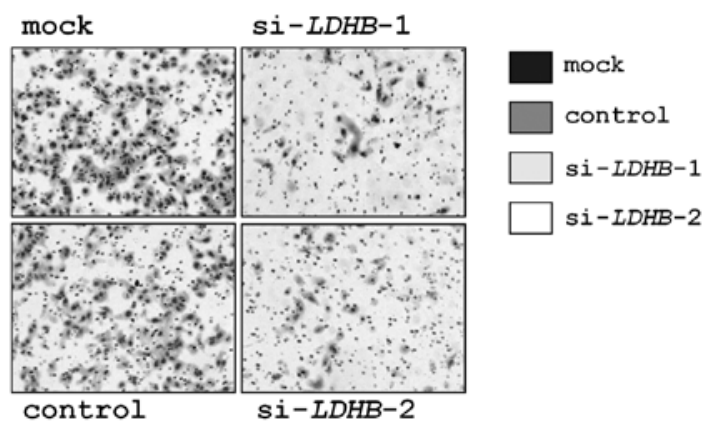

Figure 5. Loss of function studies using si- $L D H B$ transfected IMC-3 cells. (A) Cell proliferation as revealed by the XTT assay. ${ }^{*} \mathrm{P}<0.0005,{ }^{* *} \mathrm{P}<0.0001$. (B) Cell invasion activity (Matrigel invasion assay) of cells transfected with si-LDHB. ${ }^{* *} \mathrm{P}<0.0001$.

A

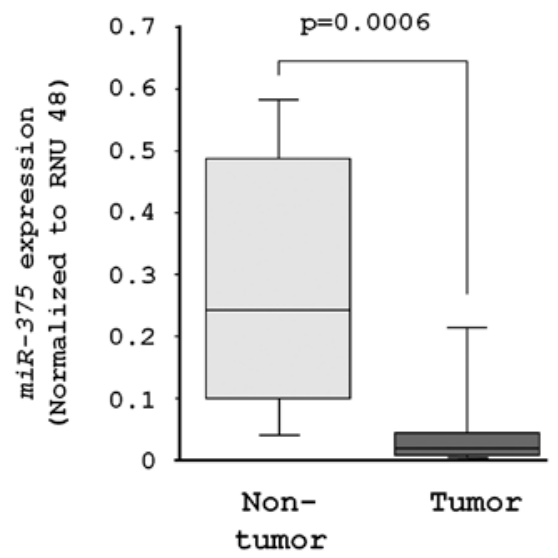

B
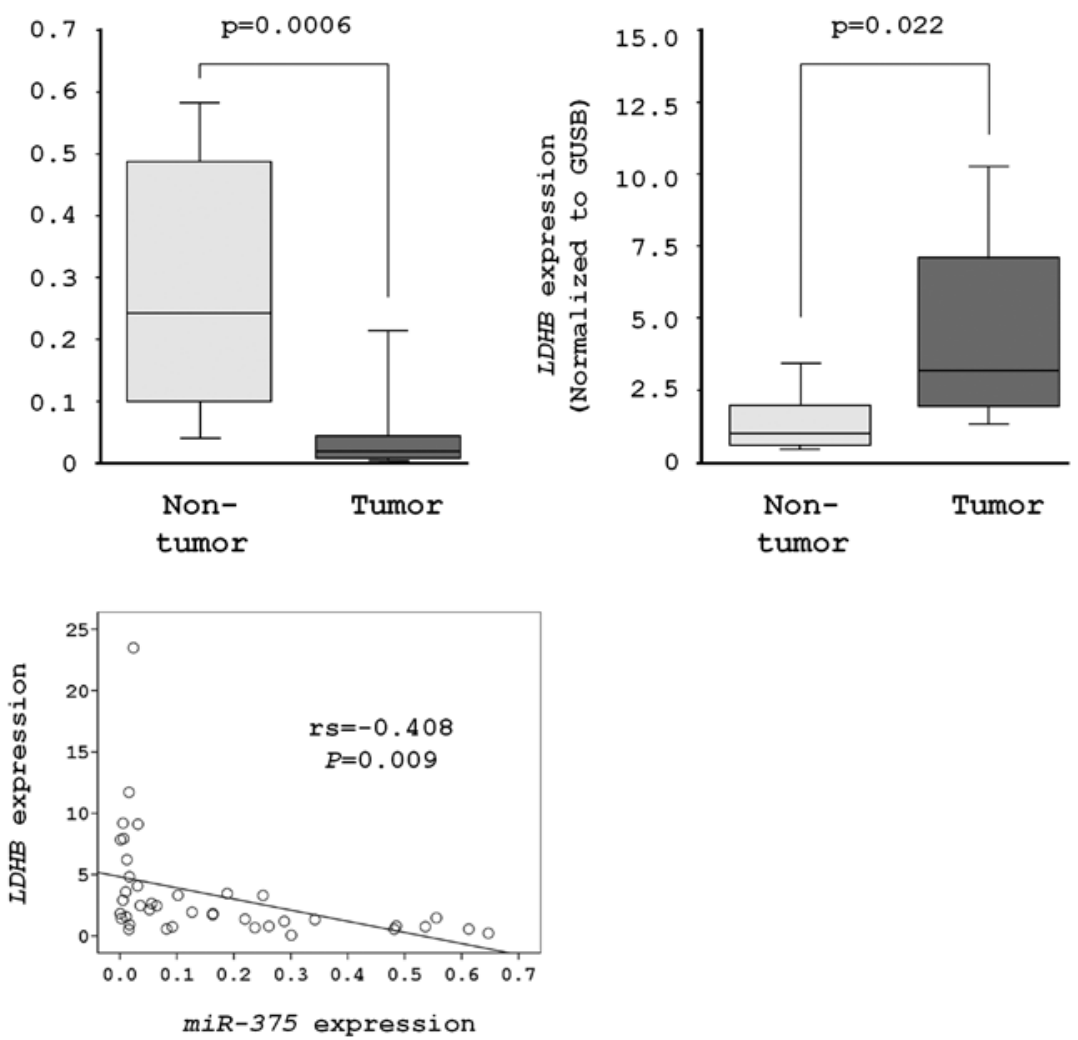

Figure 6. $m i R$-375 and $L D H B$ mRNA expression in 20 clinical MSSCC specimens. (A) $m i R-375$ expression in normal adjacent issues and tumor tissues. (B) $L D H B$ mRNA expression in tumor tissues and normal adjacent tissues. (C) Correlation between $m i R-375$ expression and $L D H B$ mRNA expression.

normal tissues ( $\mathrm{P}=0.0006$, Fig. 6A). Conversely, $L D H B$ mRNA was significantly up-regulated in tumor tissues $(\mathrm{P}=0.022$, Fig. 6A). The expression of $m i R-375$ was inversely correlated with that of $L D H B$ (Fig. 6B).
To determine if the levels of $L D H B$ of tumor tissues correlate with the survival of the MSSCC patients, we categorized two groups according to $L D H B$ mRNA expression. As the results of statistical analysis, patients with high $L D H B$ expression group 


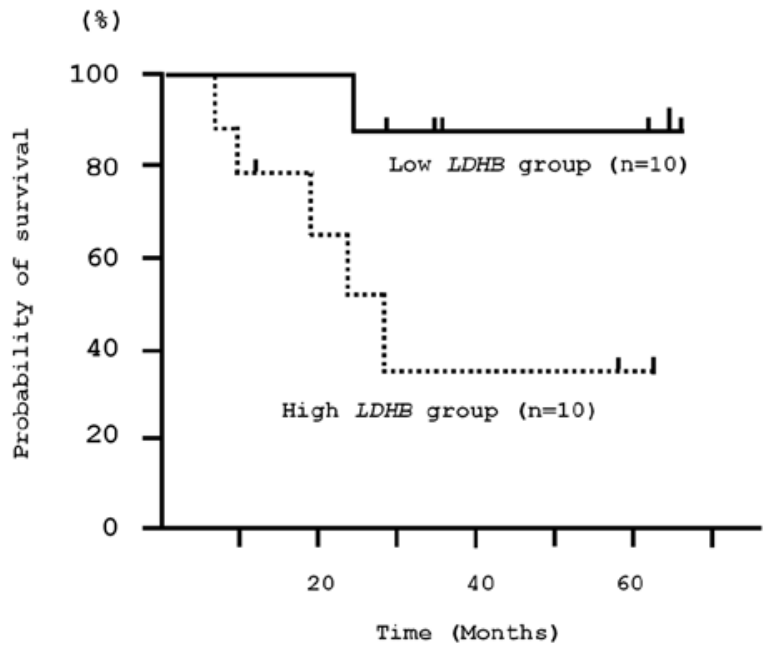

Figure 7. Kaplan-Meier analysis of overall survival in patients with MSSCC. Twenty MSSCC patients were divided into 2 groups on the basis of whether $L D H B$ mRNA expression levels were higher or lower than the median. Kaplan-Meier analysis indicates the correlation between the overall survial of MSSCC patients and mRNA expression levels of $L D H B$. The log-rank test showed statistically significant difference between the 2 groups. $(\mathrm{P}=0.035)$.

showed worse survival rate than low $L D H B$ expression group (five-year overall survival rate: 35 and $88 \%$, respectively). The log-rank test showed statistically significant difference between the 2 groups ( $\mathrm{P}=0.035$; Fig. 7$)$.

\section{Discussion}

Aberrant expression of miRNAs and uncontrolled gene expression of tumor suppressors and oncogenes contribute to the initiation and development of human cancers (11). We have identified tumor suppressive miRNAs and their associated cancer networks based on miRNA expression signatures (13-16). A comparison of these expression signatures (hypopharyngeal and esophageal SCC) with reports from other institutes found that $m i R-375$ is significantly down-regulated in several types of cancers $(23,25,26,29,30)$. An expression signature of MSSCC in our recent study revealed that $m i R-375$ is also reduced (third down-regulated miRNA in this profile) in cancer tissues (data not shown).

Therefore, we investigated the functional significance of $m i R-375$ in MSSCC in this study. The data revealed that restoration of $m i R-375$ suppressed cancer cell proliferation and invasion in IMC-3 cells, confirming results from an analysis of other region of HNSCC (31). The tumor suppressive function of $m i R-375$ has also been reported with other cancers, such as gastric cancer and liver cancer $(23,25,26,32)$. These data strongly indicate that $m i R-375$ acts as a tumor suppressor in human cancers.

The unique point of miRNA biogenesis is that one miRNA regulates many protein-coding genes. That is why the elucidation of a miRNA-regulated cancer network is important in understanding human cancer. According to the past studies, miR-375 directly regulates the YWHAZ/14-3-3\}, PDK1, YAP and $J A K 2$ genes in several cancers $(23,25,26)$. More recently, we also reported that $m i R-375$ directly regulates an oncogene $A E G-1 / M T D H$ in HNSCC (31). Microarray analyses of MSSCC (this study) found that the expression levels of $Y W H A Z / 14-3-3 \xi$ was conspicuously reduced in $m i R-375$ transfectants. There are many studies that $Y W H A Z / 14-3-3 \xi$ functions as an oncogene in several human cancers, including $\operatorname{HNSCC}(33,34)$. In addition, YWHAZ/14-3-3६ is located on human chromosome 8q22.3, a region that is frequently the site of copy number gain in HNSCC (35). Overexpression of $A E G-1 / M T D H$, an oncogene under direct regulation of $m i R-375$, was observed in several types of cancers (36-38). Many studies have indicated that $A E G-1 / M T D H$ contributes to several steps in human oncogenesis, including cancer cell progression, invasion, metastasis, and chemoresistance (39). It is reported that overexpression of $A E G-1 /$ $M T D H$ promotes activation of the pro-survival pathway of PI3K/AKT via up-regulation of PIP3 (40). These facts suggest that $m i R-375$ is a direct regulator of the $Y W H A Z / 14-3-3 \xi$ and $A E G-1 / M T D H$ oncogenes, and that this phenomenon is important to HNSCC and MSSCC oncogenesis.

The novel finding of this study is that $L D H B$ is directly regulated by $m i R-375$ in MSSCC. $L D H B$ and $L D H A$ are the glycolytic enzymes that catalyze the formation of lactic acid from pyruvate (41). It has been reported that $L D H A$ is elevated and activated in many cancers $(42,43)$. However, a definitive relationship between $\angle D H B$ and cancer has not been established. In non-small cell lung cancer (NSCLC), the levels of LDHB were significantly elevated in NSCLC sera. Furthermore, the serum levels of LDHB correlated with the clinical stage of NSCLC (41), and concomitant protein expression of LDHB and CCNB1 was a predictor of very poor prognosis in medulloblastoma patients (44). Our data also indicated that mRNA levels of $L D H B$ were elevated in cancer tissues. More interestingly, Kaplan-Meier curves and log-rank tests revealed the high mRNA expression levels of $L D H B$ had a significant adverse effect on survival rate. Our results show the possibility that $L D H B$ becomes the prognostic marker of MSSCC. However, our cohort was too small to evaluate this relationship.

A recent study on the role of $\angle D H B$ in cancer signaling pathways reported that $\angle D H B$ is a downstream target of $m T O R$, which is critical for oncogenic $m T O R$-mediated tumorigenesis (45). Our data revealed that cell proliferation was significantly reduced in si- $L D H B$ transfectants, suggesting that downregulation of $m i R-375$ and up-regulation of $L D H B$ is an indispensable event for MSSCC initiation and development. A detailed study of $m i R-375$-regulated molecular networks is needed for full understanding of human oncogenesis.

In conclusion, the reduction of $m i R-375$ and the increased expression of $L D H B$ are frequent events in MSSCC cancer cells. $m i R-375$ functions as a tumor suppressor and direct regulator of $L D H B$ in MSSCC. The miR-375 regulation of novel cancer pathways could provide new insights into the molecular mechanisms involved in the development of MSSCC and contribute to the development of new therapeutic strategies for the disease.

\section{Acknowledgements}

This study was supported by JSPS KAKENHI(C) 21592187.

\section{References}

1. Tiwari R, Hardillo JA, Mehta D, et al: Squamous cell carcinoma of maxillary sinus. Head Neck 22: 164-169, 2000. 
2. Dulguerov P, Jacobsen MS, Allal AS, Lehmann W and Calcaterra T: Nasal and paranasal sinus carcinoma: Are we making progress? A series of 220 patients and a systematic review. Cancer 92: 3012-3029, 2001

3. Vokes EE, Weichselbaum RR, Lippman SM and Hong WK: Head and neck cancer. N Engl J Med 328: 184-194, 1993.

4. Luce D, Leclerc A, Begin D, et al: Sinonasal cancer and occupational exposures: A pooled analysis of 12 case-control studies. Cancer Causes Control 13: 147-157, 2002.

5. Mannetje Á, Kogevinas M, Luce D, et al: Sinonasal cancer, occupation, and tobacco smoking in european women and men. Am J Ind Med 36: 101-107, 1999.

6. Zheng W, McLaughlin JK, Chow WH, Chien HT and Blot WJ: Risk factors for cancers of the nasal cavity and paranasal sinuses among white men in the united states. Am J Epidemiol 138: 965-972, 1993

7. Zhang J, Chen YH and Lu Q: Pro-oncogenic and anti-oncogenic pathways: Opportunities and challenges of cancer therapy. Future Oncol 6: 587-603, 2010

8. Nelson KM and Weiss GJ: MicroRNAs and cancer: Past, present, and potential future. Mol Cancer Ther 7: 3655-3660, 2008.

9. Bartel DP: MicroRNAs: Genomics, biogenesis, mechanism, and function. Cell 116: 281-297, 2004.

10. Filipowicz W, Bhattacharyya SN and Sonenberg N: Mechanisms of post-transcriptional regulation by microRNAs: Are the answers in sight? Nat Rev Genet 9: 102-114, 2008.

11. Calin GA and Croce CM: MicroRNA signatures in human cancers. Nat Rev Cancer 6: 857-866, 2006.

12. Esquela-Kerscher A and Slack FJ: Oncomirs - microRNAs with a role in cancer. Nat Rev Cancer 6: 259-269, 2006.

13. Ichimi T, Enokida H, Okuno Y, et al: Identification of nove microRNA targets based on microRNA signatures in bladder cancer. Int J Cancer 125: 345-352, 2009.

14. Chiyomaru T, Enokida H, Tatarano S, et al: $\mathrm{miR}-145$ and miR-133a function as tumour suppressors and directly regulate FSCN1 expression in bladder cancer. Br J Cancer 102: 883-891, 2010.

15. Kano M, Seki N, Kikkawa N, et al: miR-145, miR-133a and miR-133b: Tumor-suppressive miRNAs target FSCN1 in esophageal squamous cell carcinoma. Int J Cancer 127: 2804-2814, 2010.

16. Kikkawa N, Hanazawa T, Fujimura L, et al: miR-489 is a tumour-suppressive miRNA target PTPN11 in hypopharyngeal squamous cell carcinoma (HSCC). Br J Cancer 103: 877-884, 2010.

17. Yoshino H, Chiyomaru T, Enokida H, et al: The tumoursuppressive function of miR-1 and miR-133a targeting TAGLN2 in bladder cancer. Br J Cancer 104: 808-818, 2011.

18. Mutallip M, Nohata N, Hanazawa T, et al: Glutathione S-transferase P1 (GSTP1) suppresses cell apoptosis and its regulation by miR-133 $\alpha$ in head and neck squamous cell carcinoma (HNSCC). Int J Mol Med 27: 345-352, 2011.

19. Nohata N, Hanazawa T, Kikkawa N, et al: Caveolin-1 mediates tumor cell migration and invasion and its regulation by $m i R-133 a$ in head and neck squamous cell carcinoma. Int $\mathbf{J}$ Oncol 38 : 209-217, 2011.

20. Nohata N, Sone Y, Hanazawa T, et al: $\mathrm{miR}-1$ as a tumor suppressive microRNA targeting TAGLN2 in head and neck squamous cell carcinoma. Oncotarget 2: 29-42, 2011.

21. Poy MN,Eliasson L, Krutzfeldt J, et al: A pancreatic islet-specific microRNA regulates insulin secretion. Nature 432: 226-230, 2004.

22. Poy MN, Hausser J, Trajkovski M, et al: miR-375 maintains normal pancreatic alpha- and beta-cell mass. Proc Natl Acad Sci USA 106: 5813-5818, 2009

23. Ding L, Xu Y,Zhang W, et al: MiR-375 frequently downregulated in gastric cancer inhibits cell proliferation by targeting JAK2. Cell Res 20: 784-793, 2010

24. Li X, Lin R and Li J: Epigenetic silencing of MicroRNA-375 regulates PDK1 expression in esophageal cancer. Dig Dis Sci: April 30, 2011 (Epub ahead of print).

25. Liu AM, Poon RT and Luk JM: MicroRNA-375 targets hipposignaling effector YAP in liver cancer and inhibits tumor properties. Biochem Biophys Res Commun 394: 623-627, 2010.
26. Tsukamoto Y, Nakada C, Noguchi T, et al: MicroRNA-375 is downregulated in gastric carcinomas and regulates cell survival by targeting PDK1 and 14-3-3zeta. Cancer Res 70: 2339-2349, 2010.

27. Mizoguchi H, Komiyama S, Matsui K, et al: The response to epidermal growth factor of human maxillary tumor cells in terms of tumor growth, invasion and expression of proteinase inhibitors. Int J Cancer 49: 738-743, 1991.

28. Sugimoto T, Seki N, Shimizu S, et al: The galanin signaling cascade is a candidate pathway regulating oncogenesis in human squamous cell carcinoma. Genes, Chromosomes Cancer 48: 132-142, 2009.

29. Avissar M, Christensen BC, Kelsey KT and Marsit CJ: MicroRNA expression ratio is predictive of head and neck squamous cell carcinoma. Clin Cancer Res 15: 2850-2855, 2009.

30. Hui AB, Lenarduzzi M, Krushel T, et al: Comprehensive MicroRNA profiling for head and neck squamous cell carcinomas. Clin Cancer Res 16: 1129-1139, 2010.

31. Nohata N, Hanazawa T, Kikkawa N, et al: Tumor suppressive microRNA-375 regulates oncogene AEG-1/MTDH in head and neck squamous cell carcinoma (HNSCC). J Hum Genet: 56: 595-601, 2011.

32. Xu Y, Deng Y, Yan X and Zhou T: Targeting miR-375 in gastric cancer. Expert Opin Ther Targets 15: 961-972, 2011.

33. Leivonen SK, Rokka A, Ostling P, Kohonen P, Corthals GL, Kallioniemi O and Perala M: Identification of miR-193b targets in breast cancer cells and systems biological analysis of their functional impact. Mol Cell Proteomics: April 21, 2011 (Epub ahead of print)

34. Ralhan R, Desouza LV, Matta A, et al: Discovery and verification of head-and-neck cancer biomarkers by differential protein expression analysis using iTRAQ labeling, multidimensional liquid chromatography, and tandem mass spectrometry. Mol Cell Proteomics 7: 1162-1173, 2008.

35. Lin M, Morrison CD, Jones S, Mohamed N, Bacher J and Plass C: Copy number gain and oncogenic activity of YWHAZ/14-33zeta in head and neck squamous cell carcinoma. Int J Cancer 125: 603-611, 2009.

36. Lee SG, Jeon HY, Su ZZ, et al: Astrocyte elevated gene-1 contributes to the pathogenesis of neuroblastoma. Oncogene 28 : 2476-2484, 2009

37. Warr T, Ward S, Burrows J, et al: Identification of extensive genomic loss and gain by comparative genomic hybridisation in malignant astrocytoma in children and young adults. Genes Chromosomes Cancer 31: 15-22, 2001.

38. Yu C, Chen $\mathrm{K}$, Zheng $\mathrm{H}$, et al: Overexpression of astrocyte elevated gene-1 (AEG-1) is associated with esophageal squamous cell carcinoma (ESCC) progression and pathogenesis. Carcinogenesis 30: 894-901, 2009.

39. Hu G, Wei Y and Kang Y: The multifaceted role of MTDH/ AEG-1 in cancer progression. Clin Cancer Res 15: 5615-5620, 2009.

40. Meng X, Brachova P, Yang S, Xiong Z, Zhang Y, Thiel KW and Leslie KK: Knockdown of MTDH sensitizes endometrial cancer cells to cell death induction by death receptor ligand TRAIL and HDAC inhibitor LBH589 co-treatment. PLoS One 6: e20920, 2011.

41. Chen $\mathrm{Y}$, Zhang $\mathrm{H}, \mathrm{Xu} \mathrm{A}$, et al: Elevation of serum 1-lactate dehydrogenase B correlated with the clinical stage of lung cancer. Lung Cancer 54: 95-102, 2006.

42. Lewis BC, Prescott JE, Campbell SE, Shim H, Orlowski RZ and Dang CV: Tumor induction by the c-myc target genes rcl and lactate dehydrogenase A. Cancer Res 60: 6178-6183, 2000.

43. Shim H, Dolde C, Lewis BC, et al: c-myc transactivation of LDH-A: Implications for tumor metabolism and growth. Proc Natl Acad Sci USA 94: 6658-6663, 1997.

44. de Haas T, Hasselt N, Troost D, et al: Molecular risk stratification of medulloblastoma patients based on immunohistochemical analysis of MYC, LDHB, and CCNB1 expression. Clin Cancer Res 14: 4154-4160, 2008.

45. Zha X, Wang F, Wang Y, He S, Jing Y, Wu X and Zhang H: Lactate dehydrogenase $\mathrm{B}$ is critical for hyperactive mTORmediated tumorigenesis. Cancer Res 71: 13-18, 2011. 